\title{
Hydroxyl accessibility in wood cell walls as affected by drying and re-wetting procedures
}

\author{
Emil Engelund Thybring $\mathbb{D} \cdot$ Lisbeth Garbrecht Thygesen • Ingo Burgert
}

Received: 15 August 2016/Accepted: 27 March 2017/Published online: 30 March 2017

(C) The Author(s) 2017. This article is an open access publication

\begin{abstract}
The first drying of wood cell walls from the native state has sometimes been described as producing irreversible structural changes which reduce the accessibility to water, a phenomenon often referred to as hornification. This study demonstrates that while changes do seem to take place, these are more complex than what has hitherto been described. The accessibility of wood cell wall hydroxyls to deuteration in the form of liquid water was not found to be affected by drying, since vacuum impregnation with liquid water restores the native cell wall accessibility. Contrary to this, hydroxyl accessibility to deuteration by water vapour was found to decrease to different levels depending on the drying conditions. Vacuum drying at $60{ }^{\circ} \mathrm{C}$ for 3 days reduced the
\end{abstract}

Electronic supplementary material The online version of this article (doi:10.1007/s10570-017-1278-x) contains supplementary material, which is available to authorized users.

E. E. Thybring $(\bowtie) \cdot$ L. G. Thygesen

Department of Geosciences and Natural Resource

Management, University of Copenhagen, Rolighedsvej

23, 1958 Frederiksberg C, Denmark

e-mail: eet@ign.ku.dk

E. E. Thybring $\cdot$ I. Burgert

Institute for Building Materials, Wood Materials Science, ETH Zürich, Stefano-Franscini-Platz 3, 8093 Zürich, Switzerland

E. E. Thybring $\cdot$ I. Burgert

Applied Wood Materials, EMPA, Ueberlandstrasse 129, 8600 Dübendorf, Switzerland accessibility more than drying for 1 day at $103{ }^{\circ} \mathrm{C}$ without vacuum. Drying for 3 days at $103{ }^{\circ} \mathrm{C}$ increased the hydroxyl accessibility compared to 1 day. Moreover, the decrease in hydroxyl accessibility to deuteration by water vapour induced by the first drying could be at least partially erased by subsequent vacuum impregnation with liquid water, indicating reversibility. For the drying of solid, non-degraded wood cell walls the results challenge the often supposed process of hornification, understood as a permanent decrease in hydroxyl accessibility to water.

Keywords Hydroxyl accessibility · Deuterium exchange $\cdot$ DVS $\cdot$ ATR-FTIR $\cdot$ Wood

\section{Introduction}

In the native state, sapwood xylem cell walls are fully saturated with and swollen by water. By the first drying from this state, the cell wall structure gradually collapses as water is removed and cell walls enter a state never experienced before. Hence, the first drying from native state has been reported to produce irreversible changes to the structure (Suchy et al. 2010b). As moisture is removed from cell walls during drying, some of the constituent molecules are thought to collapse into hydrogen-bonded configurations that cannot be fully re-wetted by water (Kontturi and Vuorinen 2009; Suchy 2011; Suchy et al. 2010a, b). 
This phenomenon of lower hydroxyl accessibility is well-known for some types of wood pulps and is termed hornification. Disagreement has been reported over its cause (Fernandes Diniz et al. 2004), but a possible interpretation of more recent studies is that aggregation of cellulose fibrils due to hemicellulose and lignin removal and/or relocation could be involved (Laivins and Scallan 1996; Langan et al. 2014; Pönni et al. 2014a). That interactions with water can produce structural changes which are not easily reversed is agreed for smaller sugar molecules. For instance, amorphous sugars such as sucrose, glucose (Makower and Dye 1956) and lactose (Torres et al. 2011) exhibit a decreasing accessibility for water if stored above certain threshold humidity due to crystallisation. The dominant sugar-based macromolecule of wood cell walls, cellulose is known for its ability to form very stable aggregated structures which are only accessible for water in harsh physical conditions of elevated temperature and pressure (above $200{ }^{\circ} \mathrm{C}$ and $25 \mathrm{MPa}$; Deguchi et al. 2008). Although cellulose is also thermally degraded under such conditions (Tolonen et al. 2011, 2013), the crystals are seen to completely dissolve in water under very short reaction times (less than $10 \mathrm{~s}$ ) forming amorphous cellulose fragments (Deguchi et al. 2008; Tolonen et al. 2013), which nonetheless re-crystallises upon drying (Tolonen et al. 2011). From this it is seen that cellulose has an innate tendency to form aggregated structures which are partly inaccessible for water. Furthermore, spectroscopic investigations by Atalla et al. (2014) show that drying of gently isolated cellulose microfibrils and re-wetting with $\mathrm{D}_{2} \mathrm{O}$ gave lower hydroxyl accessibility compared with never-dried microfibrils. More dramatic changes were, however, observed for cellulose isolated with commonly applied procedures using elevated temperatures, e.g. cooking during pulping. Similarly, hydroxyl accessibility to liquid water in bacterial cellulose (Lee and Bismarck 2012) and cotton cellulose (Atalla et al. 2009) have been found to be higher in the never-dried state than after drying and re-wetting. When situated inside wood cell walls, however, cellulose microfibrils have hemicelluloses and lignin filling up the space between them (Salmén 2015; Salmén and Burgert 2009). These matrix polymers are amorphous, i.e. they do not form aggregated, crystalline structures, and it can be speculated that this limits the possibility for cellulose aggregation inside drying cell walls. For instance, it has been observed that the presence of hemicelluloses in pulps significantly reduces hornification upon drying (Laivins and Scallan 1996; Oksanen et al. 1997). Furthermore, Leppänen et al. (2011) investigated the behaviour of cell wall structures during first drying from native state of birch, aspen and hybrid aspen and found that the disorder of constituent molecules increased. If first drying irreversibly decreases accessibility to liquid water, an increase in the ordering of molecules as described in (Atalla et al. 2014) would have been expected as the structure collapses into energetically favourable (ordered) configurations. In other words, the results of Leppänen et al. (2011) would indicate that hornification understood as a permanent decrease in hydroxyl accessibility due to formation of stable, aggregated, energetically favourable molecular conformations does not occur in solid, non-degraded wood cell walls during drying.

When it comes to accessibility to water in the form of vapour, previous results indicate that compete rewetting after drying from the native state is not possible by exposing wood to water vapour, but can only be obtained by vacuum impregnation with liquid water. This is seen by the ability of liquid water to restore desorption equilibrium moisture contents to those of the first drying isotherm (Hoffmeyer et al. 2011). However, the difference in the number of accessible hydroxyl groups between wood exposed to water in liquid and vapour form have not been studied previously.

Deuterated water has been used in a number of studies to assess wood cell wall hydroxyl accessibility to water (Altaner et al. 2006; Chow 1972; Fackler and Schwanninger 2011; Fernandes et al. 2011; Kontturi and Vuorinen 2009; Suchy 2011; Suchy et al. 2010a, b; Sumi et al. 1964; Taniguchi et al. 1966, 1978), as functional groups capable of forming H-bonded complexes with water can have their hydrogen exchanged with deuterium (Englander et al. 1972). This exchange can be detected by spectroscopic or gravimetric techniques, both of which are employed in the current study. By wetting a biopolymeric material with heavy water $\left(D_{2} \mathrm{O}\right)$, protium ("normal" hydrogen, $\mathrm{H}$ ) will be replaced by deuterium (D) in water-interacting functional groups. By supplying a vast amount of $\mathrm{D}_{2} \mathrm{O}$ compared to the amount of water-interacting functional groups, all of these will after a while contain D instead of H. Hereby, 
the material dry mass will be increased by $1 \mathrm{~g}$ per mol exchanged hydrogen, and absolute hydroxyl accessibility can be determined gravimetrically if the specimen is dried under circumstances preventing reprotonation, i.e. exchange of D back to $\mathrm{H}$ (Sepall and Mason 1961; Wadehra and Manley 1966). In the second approach the effect of deuterium exchange on infrared spectroscopic fingerprints of hydrogen containing molecules is utilised (Gold and Satchell 1955). For instance, stretching vibrations of $\mathrm{O}-\mathrm{H}, \mathrm{N}-\mathrm{H}$, and $\mathrm{C}-\mathrm{H}$ are shifted to lower wavenumbers by roughly 1000,900 , and $800 \mathrm{~cm}^{-1}$, respectively, compared to the same vibrations without deuterium. For wood and its constituent polymers, the interactions with water is dominated by hydroxyl-water bonds as seen by the absence of a C-D stretching peak and the unchanged nature of the $\mathrm{C}-\mathrm{H}$ stretching peak after deuteration (Hofstetter et al. 2006; Mann and Marrinan 1956a; Schmidt et al. 2006; Taniguchi et al. 1966; Watanabe et al. 2006). Therefore, focusing on $\mathrm{OD}$ and $\mathrm{OH}$ stretching peaks and assuming that Beer's law holds, the relative hydroxyl accessibility can be determined by the ratio of areas of OD to OD + OH (Suchy et al. 2010b; Taniguchi et al. 1966) or alternatively by the ratio of weighted intensities of $\mathrm{OH}$ and OD peaks (Mann and Marrinan 1956b; Sepall and Mason 1961).

In this study, the state of cell walls of Norway spruce sapwood in native state (1 in Fig. 1) and after drying from this state ( 2 in Fig. 1) is examined in terms of hydroxyl accessibility for water assessed by deuterium exchange using both $\mathrm{D}_{2} \mathrm{O}$ vapour and liquid $\mathrm{D}_{2} \mathrm{O}$. The purpose is to determine how accessibility changes with different drying procedures from native state and by subsequent re-wetting with water vapour (3b in Fig. 1) or re-saturation with liquid water (3a in Fig. 1).

\section{Materials and method}

Materials and drying/wetting methods

Sample material of Norway spruce (Picea abies L.) grown at a trial site in Palsgård, Denmark (Holmsgaard and Bang 1977) was used. The trial site was established in 1964-1965 by the Danish Forest and Landscape Research Institute, and the trees used in the current study were felled in 2013. From the tree stems, discs at a height of $1.30 \mathrm{~m}$ from the ground were cut out and stored in liquid water with $0.5 \%$ sodium azide (fungicide) in a refrigerator. Material from the sapwood zone were cut out and thoroughly washed in demineralised water before further treatment. The drying techniques involved both conventional oven-drying at $103{ }^{\circ} \mathrm{C}$ for 1-3 days and vacuum-drying in a vacuum-oven at $60{ }^{\circ} \mathrm{C}$ (0 mbar) for 3 days. Water saturation after first drying was achieved by vacuum impregnation where samples were put under vacuum in a reaction flask for $5 \mathrm{~min}$ followed by injection of liquid water into the flask. Hereafter, the saturation pressure was kept for $15 \mathrm{~min}$ before atmospheric pressure was restored and samples left to soak overnight.

Spectroscopically determined hydroxyl accessibility to liquid $\mathrm{D}_{2} \mathrm{O}$

Infrared spectroscopy was employed to determine hydroxyl accessibility in the wet, native state (1 in Fig. 1) and in the re-saturated state after first drying ( $3 \mathrm{a}$ in Fig. 1) using a Bruker Tensor 27 ATR-FTIR (Bruker Optik GmbH, Fällanden, Switzerland). Batches of 5 replicate samples of app. $20 \times 10 \times 2 \mathrm{~mm}^{3}(\mathrm{~L} \times$ $\mathrm{T} \times \mathrm{R}$ ) were deuterated in flasks with $50 \mathrm{~mL}$ liquid $\mathrm{D}_{2} \mathrm{O}$ (99.9\%-atom, Sigma Aldrich Chemie GmbH, Buchs, Switzerland) and were either stirred for $4 \mathrm{~h}$ (GREEN batch) or were subjected to three $1 / 2 \mathrm{~h}$ cycles of vacuum (2.0-2.5 mbar) interrupted by $1 / 2 \mathrm{~h}$ at atmospheric pressure, reinstated with dry nitrogen gas (GREENVAC, VACDRY, and OVENDRY batches). Hereafter, the solvent was exchanged for a fresh batch of $50 \mathrm{~mL} \mathrm{D}_{2} \mathrm{O}$, each flask was purged with dry nitrogen and left for $24 \mathrm{~h}$ to push the equilibrium as far as possible toward full deuteration. After this, all specimens were dried in a vacuum oven at $60{ }^{\circ} \mathrm{C}, 0$ mbar for $24 \mathrm{~h}$. To avoid re-protonation by exchange with moisture in the air, dry nitrogen gas was used to reinstate atmospheric pressure in the oven after drying. For sample batches not subject to re-protonation, each specimen was put into a glass container with molecular sieves $3 \AA$ (Sigma Aldrich Chemie GmbH, Buchs, Switzerland) to avoid re-protonation by interaction with moist air. The relative amount of inaccessible hydroxyls after drying was determined for sub-batches of GREEN, GREENVAC, VACDRY, and OVENDRY samples which were re-protonated after being exposed to laboratory climate conditions for $2-3$ weeks. This was done by putting each batch into $50 \mathrm{~mL}$ of $\mathrm{H}_{2} \mathrm{O}$ and either sporadically stirred or vacuum saturated, resembling the 


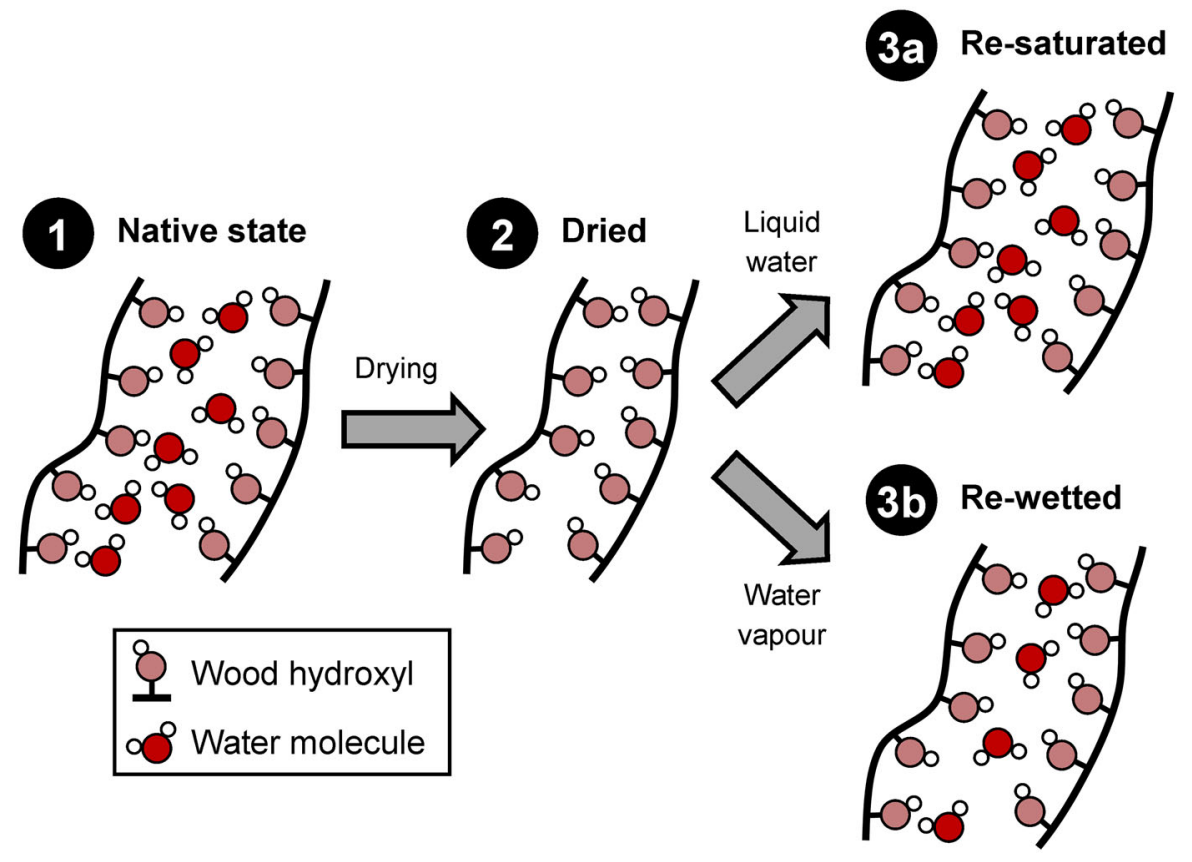

Fig. 1 Schematic illustration of water molecules confined within the wood cell wall polymers. The accessibility for water to wood hydroxyls is determined by the ATR-FTIR method in states 1 and $3 a$ and by the DVS method in state $3 b$. In the ATRFTIR method, hydroxyl accessibility is given relative to the total

reverse processes employed for deuteration. Thus, after 4-5 h of re-protonation the liquid was replaced by a fresh batch of $50 \mathrm{~mL} \mathrm{H}_{2} \mathrm{O}$ and left for another $24 \mathrm{~h}$. Hereafter, the same vacuum drying and transportation procedures as before were employed before infrared spectroscopic investigations.

For determination of hydroxyl accessibility, samples were taken out of their glass container, cut along the grain approximately in the middle of the shortest dimension and the freshly cut surface put quickly onto the diamond ATR crystal. It took around 10-20 s between cutting of specimens and measuring the infrared spectrum $\left(400-4000 \mathrm{~cm}^{-1}, 64\right.$ scans, $60 \mathrm{~s}$ in total). All acquired spectra were analysed using OPUS Version 7.2 (Bruker Optik GmbH, Fällanden, Switzerland). Spectra were baseline corrected using the concave rubberband method ( 10 iterations, 64 baseline points) and max-min normalised. Areas under $\mathrm{OH}$ and OD stretching peaks were determined by numerical integration. The $\mathrm{OH}$ peak area was calculated in the interval $3000-3700 \mathrm{~cm}^{-1}$, while the OD area was found as double the area between $2700 \mathrm{~cm}^{-1}$ and peak height (around $2510 \mathrm{~cm}^{-1}$ ), see Fig. 2. The latter was amount of hydroxyls, whereas the DVS method provides the absolute amount of accessible hydroxyls (exposed to $\mathrm{D}_{2} \mathrm{O}$ vapour at $95 \%$ relative humidity). Three different drying protocols are employed: air-drying, vacuum drying at $60{ }^{\circ} \mathrm{C}$, and oven drying at $103{ }^{\circ} \mathrm{C}$

done to avoid contributions from $\mathrm{CO}_{2}$ vibrations found around $2300-2400 \mathrm{~cm}^{-1}$. Finally, relative hydroxyl accessibility was calculated as $\mathrm{OD} /(\mathrm{OH}+\mathrm{OD})$.

Gravimetrically determined hydroxyl accessibility to $\mathrm{D}_{2} \mathrm{O}$ vapour

Dynamic Vapour Sorption equipment (DVS-ET1, Surface Measurement Systems, London, UK) was used to measure hydroxyl accessibility gravimetrically after initial drying and re-wetting with water vapour ( $3 \mathrm{~b}$ in Fig. 1). This was done by cutting specimens (5-10 mg) into very thin sections with a razor blade and conditioning them for $10 \mathrm{~h}$ at $95 \% \mathrm{RH}$ using $\mathrm{D}_{2} \mathrm{O}(99.9 \%$ atom, Sigma Aldrich Chemie GmbH, Buchs, Switzerland). Specimens were air-dried (7 replicates) or dried in conventional (3 replicates) or vacuum oven (3 replicates). The specimens were either of pure earlywood or latewood, since working with the gravimetrical method made clear that these tissues have dissimilar hydroxyl accessibilities. Thus, chips (20 mm length, $\sim 10 \mathrm{~mm}$ width, and various thicknesses) of pure earlywood and pure latewood were produced before the initial drying 


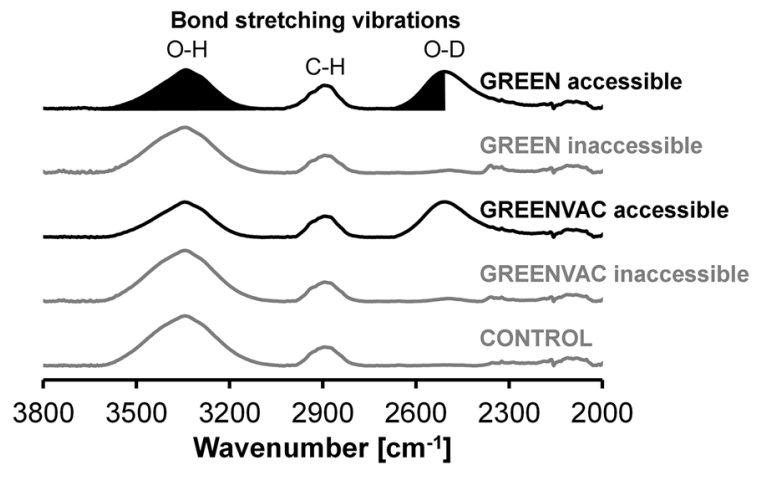

Fig. 2 Average ATR-FTIR spectra in the range $2000-3800 \mathrm{~cm}^{-1}$ of deuterated (black lines) and protonated (grey lines) Norway spruce sample batches. Spectra showing hydroxyls accessible for deuteration (O-D peak) are made after exposure to liquid $\mathrm{D}_{2} \mathrm{O}$ and vacuum dried, while those showing inaccessible hydroxyls (O-D peak) are made subsequently on deuterated batches exposed to liquid $\mathrm{H}_{2} \mathrm{O}$ and vacuum dried. GREEN native state flushed with liquid $\mathrm{D}_{2} \mathrm{O}$ and $\mathrm{H}_{2} \mathrm{O}$, GREENVAC native state, vacuum impregnated with liquid $\mathrm{D}_{2} \mathrm{O}$ and $\mathrm{H}_{2} \mathrm{O}$, CONTROL native state in liquid $\mathrm{H}_{2} \mathrm{O}$. Average spectra based on five replicates except for "GREEN accessible" and "GREENVAC accessible" with four replicates. The black part of the $\mathrm{O}-\mathrm{H}$ and $\mathrm{O}-\mathrm{D}$ peaks illustrate the areas used in calculating the relative hydroxyl accessibility. Only the area between $2700 \mathrm{~cm}^{-1}$ and $\mathrm{O}-\mathrm{D}$ peak height wavenumber (around $2510 \mathrm{~cm}^{-1}$ ) was determined to avoid contributions from $\mathrm{CO}_{2}$ vibrations in the $2300-2400 \mathrm{~cm}^{-1}$ range. The determined half O-D peak area was then doubled for accessibility determinations

from native state was commenced. Before and after each conditioning period, the dry sample mass was determined by using the built-in heating coil for increasing the temperature locally to $60{ }^{\circ} \mathrm{C}$ for $6 \mathrm{~h}$ followed by a $1 \mathrm{~h}$ thermal stabilisation period, both while purging with dry nitrogen gas. Only one conditioning step was applied since it was found that the determined accessibility depends on time of exposure and not on the number of repeated conditioning cycles as has also been reported by others (Pönni et al. 2013). Furthermore, previous experiments using longer times of conditioning had shown that the employed conditioning duration was sufficient for providing full deuteration of the accessible hydroxyls.

\section{Results and discussion}

Hydroxyl accessibility to liquid $\mathrm{D}_{2} \mathrm{O}$

The change in hydroxyl vibrations due to deuteration is illustrated in Fig. 2 average spectra for the GREEN and GREENVAC batches (black lines). Based on the individual spectra, the native state relative hydroxyl accessibility is calculated and is shown in Fig. 3 to be about $40-45 \%$ of hydroxyls accessible to liquid water in line with other studies on wood (Altaner et al. 2006; Chow 1972; Fackler and Schwanninger 2011; Fernandes et al. 2011; Taniguchi et al. 1966). This is, however, lower than the theoretically estimated accessibility which includes all hydroxyls in lignin and hemicelluloses as well as those cellulose microfibril surface hydroxyls accessible for deuteration, see electronic supplementary material.

The true relative accessibility might, however, differ from both results of the present study and theoretical estimations (electronic supplementary material) because of inherent problems with the spectroscopic method caused by dissimilar molar absorptivities of $\mathrm{OH}$ and $\mathrm{OD}$ stretching vibrations (Crawford 1952; Mann and Marrinan 1956b). For instance, the OD stretching vibrations in cellulose and starch were found to be about $10 \%$ more intense than OH stretching vibrations (Mann and Marrinan 1956b; Nara et al. 1981) which would increase the spectroscopically determined accessibility. On the other hand, OD vibrations are theoretically expected to be

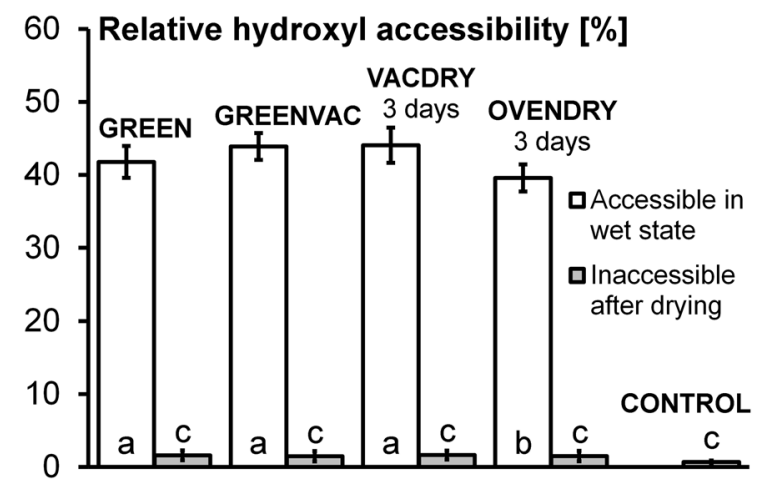

Fig. 3 Relative hydroxyl accessibility in the native state of Norway spruce and after vacuum and oven drying determined spectroscopically with ATR-FTIR after exposure to liquid $\mathrm{D}_{2} \mathrm{O}$ and subsequent vacuum drying (white bars). Also shown is the relative inaccessible hydroxyl content (grey bars) after first drying and re-protonation with liquid $\mathrm{H}_{2} \mathrm{O}$. Letters indicate statistical significant $(\alpha=95 \%)$ different sample populations. Thus, similar letters indicate non-significantly different populations. GREEN native state flushed with liquid $\mathrm{D}_{2} \mathrm{O}$ and $\mathrm{H}_{2} \mathrm{O}$, GREENVAC native state, vacuum impregnated with liquid $\mathrm{D}_{2} \mathrm{O}$ and $\mathrm{H}_{2} \mathrm{O}, V A C D R Y$ vacuum dried at $60{ }^{\circ} \mathrm{C}$ for 3 days and then vacuum impregnated with liquid $\mathrm{D}_{2} \mathrm{O}$ and $\mathrm{H}_{2} \mathrm{O}$, OVENDRY oven dried at $103{ }^{\circ} \mathrm{C}$ for 3 days and then vacuum impregnated with liquid $\mathrm{D}_{2} \mathrm{O}$ and $\mathrm{H}_{2} \mathrm{O}$, CONTROL native state in liquid $\mathrm{H}_{2} \mathrm{O}$ 
less intense (Crawford 1952; Swenson 1965) which is in line with studies on liquid $\mathrm{H}_{2} \mathrm{O}$ and $\mathrm{D}_{2} \mathrm{O}$ showing that the OD stretching vibrations are $29 \%$ less intense than $\mathrm{OH}$ stretching vibrations (Venyaminov and Prendergast 1997), hereby lowering the spectroscopically determined accessibility. Based on the areas of $\mathrm{OH}$ and $\mathrm{OD}$ stretching vibrations of all deuterated and protonated specimens, the data of the current study suggests that the latter vibrations are about $13 \%$ more intense, but the result is not statistically significant due variability of the determined areas. Therefore, it is uncertain if the spectroscopic method can yield quantitative results. Nonetheless, the method can show if hydroxyls become inaccessible to liquid water by drying as it detects remaining OD vibrations after subsequent re-wetting protocols. As shown in Figs. 2 and 3 , it is clear that more or less all deuterium was removed after re-saturation with liquid water as both GREEN, GREENVAC, VACDRY and OVENDRY samples only had $1-2 \%$ hydroxyls not re-protonated. Two further GREEN and GREENVAC sub-batches were never dried out between deuteration and reprotonated procedures, yet showed hydroxyl accessibilities in the range $0.4-1.2 \%$. These results should be compared with the hydroxyl accessibility determined for never-deuterated controls yielding $0.7 \%$, simply due to noise in the band region of the OD stretching vibration. Moreover, the VACDRY samples show similar hydroxyl accessibility to liquid water as GREEN samples, i.e. accessibility similar to the native state can be reestablished after vacuum-drying by use of vacuum impregnation with liquid water. Thus, contrary to previous reports in literature, e.g. (Suchy et al. 2010a), this study finds that no or close to no hydroxyls are made inaccessible upon vacuumdrying at $60{ }^{\circ} \mathrm{C}$ if re-protonation is done with liquid water. Reversibility has previously been reported for cellulosic pulps, but only for alkaline conditions (Pönni et al. 2013, 2014b). Therefore, this is the first study to report nearly full reversibility of deuteration after first drying of native state wood. The reason for the discrepancy between results of this study and those of previous studies might be differences in duration of the deuteration and re-protonation procedures. Thus, while Suchy et al. (2010a) deuterated native state wood for $60 \mathrm{~min}$ in excess liquid $\mathrm{D}_{2} \mathrm{O}$ and similar time in liquid $\mathrm{H}_{2} \mathrm{O}$ for re-protonation of dried samples, the deuteration and re-protonation durations employed in this study are 20 times longer. In both experiments, specimens are water-saturated when exposed to liquid $\mathrm{D}_{2} \mathrm{O}$ and dry when exposed to liquid $\mathrm{H}_{2} \mathrm{O}$, and this may lead to markedly different dynamics in the approach to equilibrium in the two situations. Thus, in the first case $\mathrm{D}_{2} \mathrm{O}$ molecules interdiffuse with $\mathrm{H}_{2} \mathrm{O}$ in the macro-void wood structure before interdiffusing with cell wall $\mathrm{H}_{2} \mathrm{O}$ molecules. In the last case, $\mathrm{D}_{2} \mathrm{O}$ molecules are diffusing directly into dry cell walls, however, the rate of transport in this step is significantly lower than when $\mathrm{D}_{2} \mathrm{O}$ interdiffuse with cell wall $\mathrm{H}_{2} \mathrm{O}$ molecules during deuteration (Engelund et al. 2013). Whether interdiffusion of $\mathrm{D}_{2} \mathrm{O}$ with $\mathrm{H}_{2} \mathrm{O}$ in the macro-void wood structure or $\mathrm{D}_{2} \mathrm{O}$ transport into cell walls is the rate limiting step depends on sample size. However, by comparing the results of Suchy et al. (2010a) with the current study, it appears likely that deuteration and re-protonation durations longer than $60 \mathrm{~min}$ are necessary to ensure equilibrium. The slightly lower hydroxyl accessibility in OVENDRY samples might be due to thermal degradation of the hemicelluloses after 3 days' exposure to $103{ }^{\circ} \mathrm{C}$, and will be further discussed later.

\section{Hydroxyl accessibility to $\mathrm{D}_{2} \mathrm{O}$ vapour}

This study confirms that exposing dried wood cell walls to water vapour does not lead to a re-opening of the cell wall structure in the same way as with liquid water. This can be seen from the gravimetrically determined hydroxyl accessibility to deuteration in Fig. 4. Depending on the drying protocol, the accessibility at $95 \% \mathrm{RH}$ varies significantly. Thus, vacuumdrying gives around $15 \%$ lower accessibility than oven-drying and $12 \%$ lower than air-drying. Ovendrying furthermore appears to increase the amount of hydroxyls accessible to deuteration with drying time contrary to common belief that oven-drying reduces hydroxyl accessibility.

Overall, the results are well in line with the upper limit of the theoretically estimated amount of hydroxyls accessible for deuteration in wood, see electronic supplementary material. This suggests that more or less all hydroxyls on microfibrils surfaces and in the amorphous hemicelluloses and lignin are accessible to water vapour after air-drying. However, of those on microfibril surfaces, recent results suggests that only two-thirds of water-interacting hydroxyls are accessible for deuteration as the $\mathrm{O}(3) \mathrm{H}$ hydroxyl acts solely as hydrogen bond acceptor, i.e. interacting exclusively 


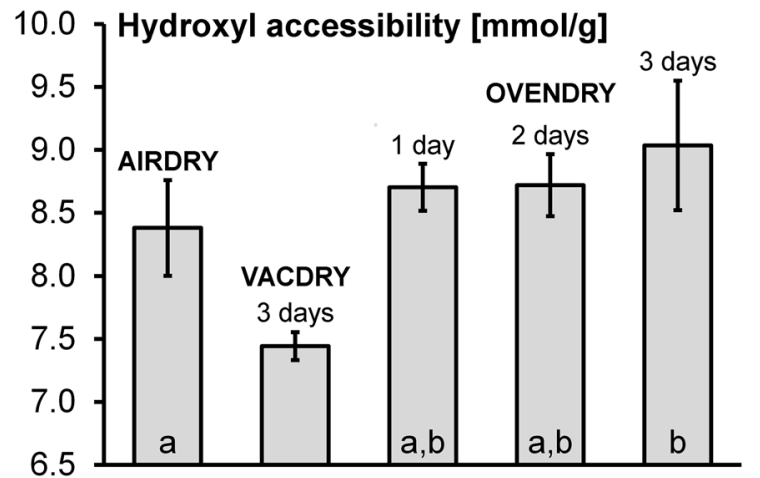

Fig. 4 Absolute hydroxyl accessibility at 95\%RH in isolated earlywood tissues of Norway spruce determined gravimetrically with DVS-ET1 after different first drying protocols. Averages and standard deviations (in brackets) calculated based on 7 replicates for the AIRDRY samples and 3 replicates for the others. Letters indicate statistical significant $(\alpha=95 \%)$ different sample populations. Thus, similar letters indicate nonsignificantly different populations. AIRDRY dried under laboratory conditions, VACDRY dried in vacuum oven at $60{ }^{\circ} \mathrm{C}$ for 3 days, $O V E N D R Y$ dried in conventional oven at $103{ }^{\circ} \mathrm{C}$ for 1 , 2 , or 3 days

with water by the $\mathrm{O}(3)$ (Lindh et al. 2016). The results for oven-dried material are slightly higher than the theoretical upper limit, which could be due to partial thermal degradation creating more hydroxyls accessible for deuteration, even though assumingly the degradation of hemicellulose would result in fewer available hydroxyls within this biopolymer. Another possibility is uncertainty in the theoretical estimates. Subsequent re-wetting by water vacuum impregnation and change of drying protocol showed that the hydroxyl accessibility was not locked by the first drying from native state as seen from Fig. 5. This figure illustrates that the air-dried material had a higher accessibility after the second drying step when this was done in a conventional oven, but the accessibility was again reduced to air-dry-level after a third drying step using a vacuum oven. On the other hand, vacuum-dried tissue had a higher accessibility after a second air-drying step.

Suggested mechanism

An important factor controlling hydroxyl accessibility after a given drying protocol is very likely the state of constituent biopolymers as the structure collapses. Amorphous polymers such as hemicelluloses and lignin can soften if water content and temperature are

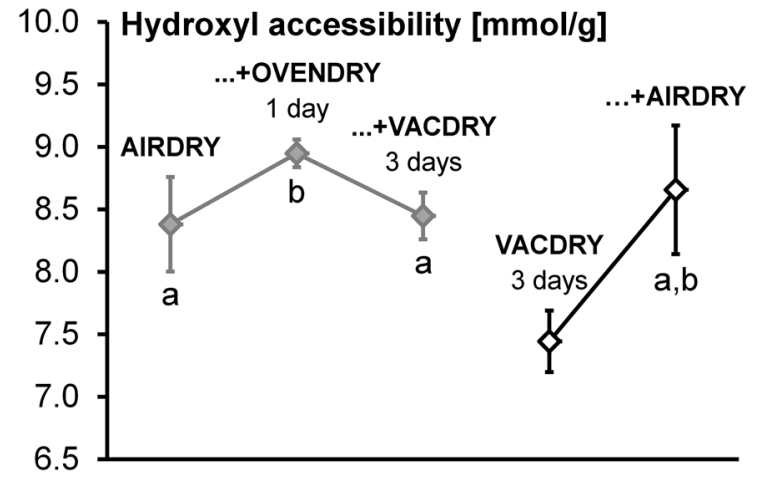

Fig. 5 Changes in absolute hydroxyl accessibility at 95\%RH in isolated earlywood tissues of Norway spruce determined gravimetrically with DVS-ET1 after different subsequent drying-wetting protocols. Wetting was done by vacuum impregnation with liquid $\mathrm{H}_{2} \mathrm{O}$. Letters indicate statistical significant $(\alpha=95 \%)$ different sample populations. Thus, similar letters indicate non-significantly different populations. $A I R D R Y$ dried under laboratory conditions, VACDRY dried in vacuum oven at $60{ }^{\circ} \mathrm{C}$ for 3 days, OVENDRY dried in conventional oven at $103{ }^{\circ} \mathrm{C}$ for 1 day

high enough. Literature data for the softening of hemicelluloses and lignin (Becker and Noack 1968; Irvine 1984; Kelley et al. 1987; Olsson and Salmén 2004; Stevens et al. 1983) as compiled by Engelund et al. (2013) shows that at water saturation, hemicelluloses are above their softening point at room temperature, while water saturated lignin needs temperatures above $60-70{ }^{\circ} \mathrm{C}$ to soften. For decreasing temperatures, more and more water is needed for the polymer to soften, most pronounced for hemicelluloses. For a given temperature, the polymer becomes rigid when the water content drops below the softening threshold corresponding to that temperature. Following the review of Engelund et al. (2013), at $103{ }^{\circ} \mathrm{C}$ the threshold water content is $5-7 \%$ for both hemicelluloses and lignin, while it is $13-15 \%$ and $18-20 \%$ for hemicelluloses at $60{ }^{\circ} \mathrm{C}$ and room temperature, respectively. For lignin, softening does not take place at room temperature, even for water saturated samples as lignin softens at around $60{ }^{\circ} \mathrm{C}$. For the exposure conditions in this study these effects imply that specimens dried at $103{ }^{\circ} \mathrm{C}$ is at high enough temperature and water content for both lignin and hemicelluloses to definitely be in a softened state even until the material reaches low water contents, whereas the hemicelluloses are softened down to intermediate water contents at $60{ }^{\circ} \mathrm{C}$ where the lignin is just around 
the softening point if water saturated. While deuteration of material vacuum dried at $60{ }^{\circ} \mathrm{C}$ is nearly completely reversible with liquid water (Fig. 3), the re-wetting with water vapour produces a lower accessibility (Fig. 4) than for samples air-dried at room temperature. Oven drying at $103{ }^{\circ} \mathrm{C}$ for 3 days on the other hand slightly reduces the accessibility to liquid water (Fig. 3) but results in a higher accessibility to water vapour (Fig. 4). These effects are also seen when dry material is re-saturated with liquid water and exposed to vacuum or oven drying (Fig. 5). If matrix polymers are softened at both levels of elevated temperature, it would appear that polymer mobility is high enough in both cases to allow formation of an ordered, aggregated structure with low accessibility upon drying, conflicting with the results for ovendrying at $103{ }^{\circ} \mathrm{C}$. One important factor in drying which may explain these results could be the rate of water removal from the drying material relative to the rate of re-organisation of the collapsing polymeric structure. The drying kinetics are much faster at elevated temperatures, which means that at lower temperatures more time is available for re-organisation and collapsing the cell wall structure in an ordered way. However, if the temperature is too low, e.g. room temperature conditions as for the air-dried material, the evaporation rate is slow, but the hemicelluloses are only softened in the initial moisture state and only until the water content reaches $18-20 \%$. Thus, only a small fraction of the matrix polymers are capable of re-arranging themselves in an ordered way and only so when the water content is high. Another factor relevant at least for longer oven drying at $103{ }^{\circ} \mathrm{C}$ is thermal degradation of the cell wall polymers of which hemicelluloses are most sensitive to elevated temperatures (Ramiah 1970). Hemicelluloses have a high concentration of hydroxyls and their thermal degradation would explain the slight decrease in accessibility to liquid water (Fig. 4). With infrared spectroscopy thermal degradation can be seen as a decrease in the vibrational peak around $1730 \mathrm{~cm}^{-1}$ (Chow 1971). This is also found in this study for oven dried material, but the decrease is not statistically significant. Nonetheless, oven drying appears to increase hydroxyl accessibility to water vapour (Figs. 4 and 5) compared with the other drying protocols. No matter the drying procedure, the exposure to liquid water is seen to re-open the collapsed cell wall structure to give a hydroxyl accessibility closely similar to that in the native state, hereby reversing any previous deuteration (Fig. 3). This explains why re-saturation and drying in the second and third cycle can increase or decrease accessibility depending on the drying protocol (Fig. 5). The effect of liquid water is, however, in contrast with that of water vapour which does not fully re-open the structure. A similar difference in the effect of liquid and vapour was seen by Hoffmeyer et al. (2011) who showed that exposure to water vapour is an insufficient re-saturation method for dried wood. This points to crucial differences in the interaction between wood and water in either liquid or gaseous form, which needs to be explored further in future studies.

\section{Conclusion}

The hydroxyl accessibility of Norway spruce to liquid water was found not to be affected by drying from the native state. Vacuum saturation with liquid water between different drying protocols was able to erase changes in accessibility produced by the previous drying process, which contradicts the often supposed hornification upon first drying. Contrary, a water vapour treatment did not fully re-open the structure and the hydroxyl accessibility was affected by the drying protocol. Drying at $103{ }^{\circ} \mathrm{C}$ resulted in a higher accessibility to water vapour than vacuum drying at $60{ }^{\circ} \mathrm{C}$ which yielded the lowest accessibility of the protocols employed. By air-drying under laboratory conditions, an intermediate hydroxyl accessibility was found. This is suggested to be explained by a specific interplay of drying rates and humidity levels in combination with the respective glass-transition temperatures of the matrix polymers.

Acknowledgments This work was mainly performed when EET was employed as Postdoc at EMPA Dübendorf. EET gratefully acknowledges financial support from FP7: People Marie-Curie action COFUND.

Open Access This article is distributed under the terms of the Creative Commons Attribution 4.0 International License (http:// creativecommons.org/licenses/by/4.0/), which permits unrestricted use, distribution, and reproduction in any medium, provided you give appropriate credit to the original author(s) and the source, provide a link to the Creative Commons license, and indicate if changes were made. 


\section{References}

Altaner C, Apperley DC, Jarvis MC (2006) Spatial relationships between polymers in Sitka spruce: proton spin-diffusion studies. Holzforschung 60:665-673

Atalla RH, Brady JW, Matthews JF, Ding SY, Himmel ME (2009) Structures of plant cell wall celluloses. In: Himmel ME (ed) Biomass recalcitrance-deconstructing the plant cell wall for bioenergy. Blackwell, Oxford, pp 188-212

Atalla RS, Crowley MF, Himmel ME, Atalla RH (2014) Irreversible transformations of native celluloses, upon exposure to elevated temperatures. Carbohydr Polym 100:2-8

Becker H, Noack D (1968) Studies on dynamic torsional viscoelasticity of wood. Wood Sci Technol 2:213-230

Chow SZ (1971) Infrared spectral characteristics and surface inactivation of wood at high temperatures. Wood Sci Technol 5:27-39

Chow SZ (1972) Hydroxyl accessibility, moisture-content, and biochemical activity in cell-walls of Douglas-fir trees. Tappi 55:539-544

Crawford B (1952) Vibrational intensities II. The use of isotopes. J Chem Phys 20:977-981

Deguchi S, Tsujii K, Horikoshi K (2008) Crystalline-to-amorphous transformation of cellulose in hot and compressed water and its implications for hydrothermal conversion. Green Chem 10:191-196

Engelund ET, Thygesen LG, Svensson S, Hill CAS (2013) A critical discussion of the physics of wood-water interactions. Wood Sci Technol 47:141-161

Englander SW, Downer NW, Teitelbaum H (1972) Hydrogenexchange. Annu Rev Biochem 41:903-924

Fackler K, Schwanninger M (2011) Accessibility of hydroxyl groups of brown-rot degraded spruce wood to heavy water. J Near Infrared Spectrosc 19:359-368

Fernandes Diniz JMB, Gil MH, Castro JAAM (2004) Hornification-its origin and interpretation in wood pulps. Wood Sci Technol 37:489-494

Fernandes AN, Thomas LH, Altaner CM, Callow P, Forsyth VT, Apperley DC, Kennedy CJ, Jarvis MC (2011) Nanostructure of cellulose microfibrils in spruce wood. Proc Natl Acad Sci USA 108:E1195-E1203

Gold V, Satchell DPN (1955) The principles of hydrogen isotope exchange reactions in solution. Q Rev Chem Soc 9:51-72

Hoffmeyer P, Engelund ET, Thygesen LG (2011) Equilibrium moisture content (EMC) in Norway spruce during the first and second desorptions. Holzforschung 65:875-882

Hofstetter K, Hinterstoisser B, Salmén L (2006) Moisture uptake in native cellulose - the roles of different hydrogen bonds: a dynamic FT-IR study using Deuterium exchange. Cellulose 13:131-145

Holmsgaard E, Bang C (1977) Et træartsforsøg med nåletræer, bøg og eg: de første 10 år (A species trial with conifers, beech and oak: the first ten years). Forstlige Fors $\emptyset$ gsvæsen $\mathrm{i}$ Danmark 35:159-196 (in Danish with English summary)

Irvine GM (1984) The glass transitions of lignin and hemicellulose and their measurement by differential thermalanalysis. Tappi J 67:118-121

Kelley SS, Rials TG, Glasser WG (1987) Relaxation behavior of the amorphous components of wood. J Mater Sci Lett 22:617-624
Kontturi E, Vuorinen T (2009) Indirect evidence of supramolecular changes within cellulose microfibrils of chemical pulp fibers upon drying. Cellulose 16:65-74

Laivins G, Scallan AM (1996) The influence of drying and beating on the swelling of fines. J Pulp Pap Sci 22:J178J184

Langan P, Petridis L, O’Neill HM, Pingali SV, Foston M, Nishiyama Y, Schulz R, Lindner B, Hanson BL, Harton S, Heller WT, Urban V, Evans BR, Gnanakaran S, Ragauskas AJ, Smith JC, Davison BH (2014) Common processes drive the thermochemical pretreatment of lignocellulosic biomass. Green Chem 16:63-68

Lee KY, Bismarck A (2012) Susceptibility of never-dried and freeze-dried bacterial cellulose towards esterification with organic acid. Cellulose 19:891-900

Leppänen K, Bjurhager I, Peura M, Kallonen A, Suuronen JP, Penttilä P, Love J, Fagerstedt K, Serimaa R (2011) X-ray scattering and microtomography study on the structural changes of never-dried silver birch, European aspen and hybrid aspen during drying. Holzforschung 65:865-873

Lindh EL, Bergenstråhle-Wohlert M, Terenzi C, Salmén L, Furó I (2016) Non-exchanging hydroxyl groups on the surface of cellulose fibrils: the role of interaction with water. Carbohydr Res 434:136-142

Makower B, Dye WB (1956) Sugar crystallization, equilibrium moisture content and crystallization of amorphous sucrose and glucose. J Agric Food Chem 4:72-77

Mann J, Marrinan HJ (1956a) The reaction between cellulose and heavy water 1 . A qualitative study by infra-red spectroscopy. Trans Faraday Soc 52:481-487

Mann J, Marrinan HJ (1956b) The reaction between cellulose and heavy water 3 . A quantitative study by infra-red spectroscopy. T Faraday Soc 52:492-497

Nara S, Takeo H, Komiya T (1981) Studies on the accessibility of starch by deuteration. Starch-Starke 33:329-331

Oksanen T, Buchert J, Viikari L (1997) The role of hemicelluloses in the hornification of bleached kraft pulps. Holzforschung 51:355-360

Olsson AM, Salmén L (2004) The softening behavior of hemicelluloses related to moisture. Acs Sym Ser 864:184-197

Pönni R, Kontturi E, Vuorinen T (2013) Accessibility of cellulose: structural changes and their reversibility in aqueous media. Carbohydr Polym 93:424-429

Pönni R, Galvis L, Vuorinen T (2014a) Changes in accessibility of cellulose during kraft pulping of wood in deuterium oxide. Carbohydr Polym 101:792-797

Pönni R, Rautkari L, Hill CAS, Vuorinen T (2014b) Accessibility of hydroxyl groups in birch kraft pulps quantified by deuterium exchange in $\mathrm{D}_{2} \mathrm{O}$ vapor. Cellulose 21:1217-1226

Ramiah MV (1970) Thermogravimetric and differential thermal analysis of cellulose, hemicellulose, and lignin. J Appl Polym Sci 14:1323-1337

Salmén L (2015) Wood morphology and properties from molecular perspectives. Ann For Sci 72:679-684

Salmén L, Burgert I (2009) Cell wall features with regard to mechanical performance. A review COST Action E35 2004-2008: wood machining-micromechanics and fracture. Holzforschung 63:121-129

Schmidt M, Gierlinger N, Schade U, Rogge T, Grunze M (2006) Polarized infrared microspectroscopy of single spruce 
fibers: hydrogen bonding in wood polymers. Biopolym 83:546-555

Sepall O, Mason SG (1961) Hydrogen exchange between cellulose and water 1. Measurement of accessibility. Can J Chem 39:1934-1943

Stevens V, Kühne G, Wienhaus O (1983) Untersuchungen zum thermoplastischen Verhalten von Ligninen (Investigations of the thermoplastic properties of lignin). Wissenschaftliche Zeitschrift der Technischen Universität Dresden 32:149-154

Suchy M (2011) Accessibility and enzymatic degradation of native and model cellulose substrates, Ph.D. thesis. Aalto University, Espoo, Finland

Suchy M, Kontturi E, Vuorinen T (2010a) Impact of drying on wood ultrastructure: similarities in cell wall alteration between native wood and isolated wood-based fibers. Biomacromol 11:2161-2168

Suchy M, Virtanen J, Kontturi E, Vuorinen T (2010b) Impact of drying on wood ultrastructure observed by deuterium exchange and photoacoustic FT-IR spectroscopy. Biomacromol 11:515-520

Sumi Y, Hale RD, Meyer JA, Leopold B, Rånby BG (1964) Accessibility of wood and wood carbohydrates measured with tritiated water. Tappi 47:621-624

Swenson CA (1965) Absolute infrared intensities of HDO in aqueous solution. Spectrochim Acta 21:987-993

Taniguchi T, Harada H, Nakato K (1966) Accessibility of hydroxyl groups in wood. Mokuzai Gakkaishi 10:215-220
Taniguchi T, Harada H, Nakato K (1978) Determination of water-adsorption sites in wood by a hydrogen-deuterium exchange. Nature 272:230-231

Tolonen LK, Zuckerstätter G, Penttilä PA, Milacher W, Habicht W, Serimaa R, Kruse A, Sixta H (2011) Structural changes in microcrystalline cellulose in subcritical water treatment. Biomacromol 12:2544-2551

Tolonen LK, Penttilä PA, Serimaa R, Kruse A, Sixta H (2013) The swelling and dissolution of cellulose crystallites in subcritical and supercritical water. Cellulose 20:2731-2744

Torres DPM, Bastos M, Goncalves MPF, Teixeira JA, Rodrigues LR (2011) Water sorption and plasticization of an amorphous galacto-oligosaccharide mixture. Carbohydr Polym 83:831-835

Venyaminov SY, Prendergast FG (1997) Water $\left(\mathrm{H}_{2} \mathrm{O}\right.$ and $\left.\mathrm{D}_{2} \mathrm{O}\right)$ molar absorptivity in the $1000-4000 \mathrm{~cm}^{-1}$ range and quantitative infrared spectroscopy of aqueous solutions. Anal Biochem 248:234-245

Wadehra IL, Manley RS (1966) Accessibility of hydrocelluloses and oligosaccharides by hydrogen exchange. Makromolekul Chem 94:42-51

Watanabe A, Morita S, Kokot S, Matsubara M, Fukai K, Ozaki Y (2006) Drying process of microcrystalline cellulose studied by attenuated total reflection IR spectroscopy with two-dimensional correlation spectroscopy and principal component analysis. J Mol Struct 799:102-110 